\title{
Mechanisms of Identity Construction among Members of Pyramid Schemes in Iran: A Critical Ethnography
}

\author{
Saeed Keshavarzi \\ Independent Researcher, Iran
}

\author{
Ali Ruhani \\ Yazd University, Iran \\ Soheyla Hajiheidari \\ Yazd University, Iran
}

DOI: https://doi.org/10.18778/1733-8077.17.4.06

Keywords:

Pyramid Scheme

Firms, Social

Construction of

Superhuman, Critical

Ethnography

\begin{abstract}
Whereas the emergence of pyramid schemes exerted considerable impacts on people's lives, up to now, far too little attention has been paid to the experiences of members from the sociological perspective, particularly in non-Western contexts. Therefore, this study illuminates social processes underlying participation in such schemes in a less studied social setting, Iran. This article also critically traces the social and psychological consequences of membership in pyramid schemes. We adapted a critical ethnographic approach, including participant observation of local branch offices, followed by 16 in-depth interviews with the former members of schemes. Our findings suggest that the practices deployed by the schemes lead to the building of social identity, namely, "superhuman," mainly based on the misinterpretation of the real world. Finding the reality surrounded deliberately contrasted with the firms' promises, the constructed identity fails, and members lose their social capital.
\end{abstract}

Saeed Keshavarzi holds a Ph.D. in political sociology from Shiraz University. He was also a Scholar at the Scuola Normale Superiore in Florence, Italy. His research focuses on different fields of study, including social movements, mobilization, collective action, political and social psychology, migration, and youth studies.

email address: saeedkeshavarzi.21@gmail.com

Ali Ruhani (corresponding author) is an Associate Professor of sociology at Yazd University. His primary research interests are qualitative methodology, critical studies, and migration. He teaches graduate and undergraduate courses in social psychology, sociology of women, introduction to sociology, and social movements.

email address: aliruhani@yazd.ac.ir

Soheyla Hajiheidari holds an MA of social research from Yazd University. Her research interests lie in critical ethnography, pyramid schemes, and social psychology. email address: soheylahajiheydari@gmail.com 


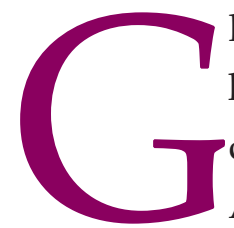

lobalized neoliberalism trends have heavily influenced human lives in recent decades (Harvey 2007a; Cahill 2011). As Karl Polanyi (1994) pointed out, the emergence of capitalist institutions followed by liberal economic ideology resulted in changes in human rules and substantially transformed human relations. At the micro-level, neoliberalism has accompanied the ideology of universal competition based on the fulfillment of insatiable financial desires to accumulate more and more, while sufficient and suitable tools to realize them are by no means accessible (Biebricher and Johnson 2012; Overbeek and Van Apeldoorn 2012). A critical transformation related to globalized neoliberalism was the growth of "consumption management" (Dyer-Witheford 1999; Robins and Webster 1999), and consequently, the "marketing phenomenon" (Eckhardt, Dholakia, and Varman 2013). These ideas have been set on the grounds of popular culture, personal relationships, and even individual mentalities (Greenwald 2010). Under the shadow of the statements on maximizing social welfare, neoliberalism provoked an array of financial crises in recent decades (Harvey 2007b). Notwithstanding, market globalization remained a solid and durable transnational trend (Eckhardt, Dholakia, and Varman 2013).

Among different types of marketing, multi-level marketing (MLM) works through independent salespeople who sell products directly to the customers while receiving a commission on their own or invite their subcontractors' sales to join the scheme (Schiffauer 2019). Accordingly, unlike the traditional styles, consumers are not approached via an appointed store anymore, but through the network of personal communications. Hence, MLM eliminates the expenditures related to the traditional stores, so that is thought to provide more profits for both sellers and customers.
Pyramid schemes (PS) are, to some extent, similar to the MLMs, but focus on recruiting new members and wealth generation instead of selling products or services (Nat and Keep 2002; Deliema et al. 2018). As PS have been widely recognized as illegal by governments, they resemble MLMs, usually disguising entry fees as the mandatory purchase price paid. Members of PS are supposed to recruit new members to make a profit; hence, they invite personal connections to join the network. Although previous studies addressed the PS or network marketing from different perspectives (e.g., Muncy 2004; Nobre and Silva 2014; Bosley and Knorr 2017), a systematic understanding of members' experience in such firms still lacks notably concerning the schemes in the non-Western context.

\section{Literature Review}

Referring to the successful experiences of people who took part in marketing networks, some scholars introduce MLM as a low-risk business or the "safest trade" (Gregor and Wadlewski 2013; Tyre 2016). Others, like Hyman (2007), evaluated MLM's initiatives as deceptive, offering impossible goals. Some scholars also pointed out that the MLM offers attractive, but reality-free promises to recruit new members (Liu 2018; Musaraj 2019), while their activities are not profitable for most members (Makni 2015; Deliema et al. 2018). Additionally, Effiom and Effiong's (2015) study showed that although MLM is a way to create wealth, it is not intended to reduce poverty in the community. More broadly, some demonstrated that although MLM firms provide opportunities for making money at the global level, they do not necessarily contribute to official job creation (Franco and Gonzalez-Perez 2016). 
Other studies pointed up the psychological consequences of network marketing, as Krige (2012) showed that participation in such firms is a sign of soullessness, lack of education, and greed. Regarding ethical issues, some believe that MLM is intrinsically inappropriate (Albaum and Peterson 2011), particularly with abusing personal connections for commercial activities (Grayson 2007; Groß and Vriens 2019), as well as causing family disputes (Pratt and Rosa 2003). Groß and Vriens (2019) summarized ethical issues caused by MLM-misleading distributors and customers via untruthful promises, imposing restrictions on customers' autonomy, and exploiting the distributors' private social relations. Focusing on the role of contextual factors, Bosley and Knorr (2017) highlighted the role of religious, social settings in flourishing MLMs. In her interesting analysis of MLM in Siberia, Schiffauer (2018) listed what motivates people to join the scheme-feelings of obligation, expectations of support and intimate pressure, and individual aspirations of making immense wealth.

PS, similar to the other social organizations, can lead to building an identity among their members (Alvesson, Ashcraft, and Thomas 2008; Gioia et al. 2013). For example, the identity might be constructed through the collective endorsement of members' roles (Brewer and Gardner 1996; DeRue and Ashford 2010) or established via an interactive acculturation process (Bourhis et al. 1997; DeRue, Ashford, and Cotton 2009). Exploring identity construction processes in network marketing organizations, Pratt (2000) underscored the role of what he calls sense-breaking and sense-giving stages. Accordingly, marketing organizations firstly break what the distributors understand from "who they are" and then try to inspire them "who they must be." The current study takes a further step to characterize the constructed identity among PS in a non-Western social setting, Iran.
Iran, alongside economic crises, has witnessed the emergence of PS in recent decades. The troubles aside, capitalism and globalization of its ideology resulted in the exponential growth of materialistic desires among the Iranian population (Akbarzadeh 1995). The sudden increase in population, a massive number of unemployed people, in addition to the pre-existed social ties (derived from pre-modern relationships) all warmed up a desirable ground for PS in Iran. In the following, we presented a brief history of PS in Iran.

\section{Pyramid Schemes in Iran}

The first PS emerged in Iran in the late 1990s. Their activities were not restricted to selling goods and services, but also organizing meetings and classes. The number of members grew exponentially thanks to the massive existing disadvantaged groups (particularly women and youth). Among all, students played an important and active role in introducing the PS to society.

Comaroff and Comaroff (2000) pointed out that reaching wealth and reaching global prosperity potentially increase the general attractions of "occult economies," including PS or, more broadly, MLM-based economic activities. It is noteworthy that in Iran, economic downturns and successive years of recession provided a suitable opportunity for PS to introduce themselves as a fascinating business. The situation recalls the notion of the "broken ladder" in the United States (Payne 2017). Adapting the Mertonian conceptualization (Merton 1938), the broken ladder refers to the inconsistency between goals and ideals valued by dominant culture and tools available to realize those ideals. What is more, the intensified social ties that existed in the Iranian context provided a favorable platform for the PS to recruit new members and exploit members' social capital. As Van Oort (2015) discussed, economic crises allow the ethnographers to contemplate the mi- 
cro-functions of the neoliberal order and explore how people in different places experience various forms of neoliberalism. Therefore, the present study was an ethnographic attempt to shed light on what members of such schemes under crisis context experience. Among all active PS, we focused on the three most popular ones in Iran. Due to the illegal nature of understudied schemes, we are not able to provide more information about their identities, but what they offer includes a variety of products from different types of cosmetics to clothes like socks and shirts.

\section{Materials and Method}

The study employed the critical ethnography method. The advantage of ethnography has been well-established; going beyond simple data descriptions and framing the analysis into the bigger context (Simon and Dippo 1986). Critical ethnography can also address the marginalized and disadvantaged people who have been unfairly and unjustly treated. Therefore, we adapted the critical ethnography proposed by Carspecken (1996); following five stages: (1) preparing the primary record; (2) preliminary reconstructive analysis; (3) discovering dialogical data generation; (4) describing system relations with a larger context; and (5) using system relationships to explain the findings. The whole research process took two years, from December of 2016 to December of 2018, whereas the data were collected during two interrelated phasesparticipant observation and in-depth interviews.

Participant observation was applied to grasp the members' experiences and the meaning systems they learn, followed by in-depth interviews to achieve more detailed information about the social processes behind the membership in the schemes. The participant observation and interviews, as follows, were carried out by the third author. Notes taken during the participant observation were used to identify relevant ideas guiding the further process of research.

In the first stage, participant observation was carried out as the third author registered in the three most popular PS in Iran. She got involved in all held events, for example, workshops, meetings, and even purchasing products. The focal point of observation gradually turned from members' experiences to the social and cultural atmosphere while notes were written. At this stage, our focus was on behaviors, speeches, and activities, especially those related to power relations. The observations provided us with information about social and cultural spaces, practices, and identities. The observation was not recorded for confidentiality purposes, but the detailed handwritten notes were taken during and immediately after each observation.

In the next step, we tried to learn about the firm's structure, domains, roles, territories, interactions, power relations, and decision-making processes via reviewing the notes taken from the previous stage. Our attention was also drawn to non-linguistic aspects, such as gestures, facial expressions, and body language. In the third stage, we carried out interviews to gain a comprehensive knowledge of members' perspectives on the firms. To select the interviewees, we relied mainly on the purposive sampling and then snowball method. Our priority during the sampling process was selecting those members with considerable experience of engagement in the firms. The first four interviewees were selected based on the preceding participant observation when the others were approached via snowball sampling. The interviews were carried out in both private and public places, depending on the participants' preferences. Table 1 provides demographic information of the interviewees. 
Table 1. Short Profiles of Research Participants

\begin{tabular}{|c|c|c|c|c|c|c|c|}
\hline & Name & Gender & Birth & Job & Marital status & $\begin{array}{l}\text { Experience } \\
\text { (Months) }\end{array}$ & Role \\
\hline 1 & Farzaneh & Female & 1988 & Housewife & Married & 6 & Member \\
\hline 2 & Fatemeh & Female & 1995 & Bachelor student & Single & 5 & Member \\
\hline 3 & Zohreh & Female & 1995 & Bachelor student & Single & 4 & Member \\
\hline 4 & Mansoureh & Female & 1986 & Housewife & Married & 12 & Counselor \\
\hline 5 & Tahereh & Female & 1992 & Make-up artist & Divorced & 16 & Counselor \\
\hline 6 & Farideh & Female & 1995 & Student & Single & 20 & Counselor Presenter \\
\hline 7 & Mahsa & Female & 1992 & Master's student & Single & 3 & Member \\
\hline 8 & Yousef & Male & 1991 & Bachelor student & Single & 24 & Leader \\
\hline 9 & Yasamin & Female & 1992 & Housewife & Married & 6 & Member \\
\hline 10 & Ehsan & Male & 1989 & Chef & Married & 15 & Member \\
\hline 11 & Shohreh & Female & 1995 & Bachelor student & Married & 12 & Member \\
\hline 12 & Mehran & Male & 1997 & Bachelor student & Single & 11 & Member \\
\hline 13 & Mostafa & Male & 1992 & Bachelor student & Single & 24 & Leader \\
\hline 14 & Mahnaz & Female & 1974 & Hairdresser & Married & 6 & Member \\
\hline 15 & Esmaeel & Male & 1993 & Conscript soldier & Single & 13 & Leader \\
\hline 16 & Mohaddeseh & Female & 1994 & Bachelor student & Single & 8 & Presenter \\
\hline
\end{tabular}

Source: Self-elaboration.

The interviews lasted an average of one hour, ranging from 40 to 60 minutes. The interviews were audiotaped and transcribed verbatim. To remain aware of the gaps and areas of further exploration and to identify questions for the next round of data collection, the participant's transcript was reviewed after each interview (Charmaz 2006). The transcribed interviews were initially coded precisely, utilizing the participants' words or expressions. As codes were associated with each other to form clusters, themes were identified, and the coding became more focused. In this section, the sampling process continued until the end of the $16^{\text {th }}$ interview, when we found the newly collected data did not offer significant knowledge to the previous findings. Themes gradually emerged on account of becoming intimate with the data, making logical associations with the interview questions, and accounting for what was understood in the light of the initial literature review.

Stages 4 and 5 were performed simultaneously, as we attempted to analyze the data from a macro-sociological perspective. Moving towards more abstraction, we tried to understand the explored processes by referring to the feature of the whole society. System analysis is at the heart of Carspecken's critical ethnography approach, which improves validity; the data obtained from the previous three stages were analyzed by referring to institutional, political, and social elements (Stewart and Usher 2007).

The reliability of the findings was confirmed through the following stages: (1) long-term participation and continuous observation in the field of 
research; (2) peer review; (3) participant confirmation; (4) external audit (Creswell and Miller 2000). Besides, following Mauthner and Doucet (2003), we adapted reflexive accounts through all stages of data analysis.

\section{Ethical Considerations}

As PS have been unexceptionally recognized as illegal in Iran, members are usually reluctant to be approached by non-members. To help to mitigate the concerns, mutual friends and participants often initially opened the channels of communication, which alleviated the fears from prosecution. Participants were also provided with documented agreements that guarantee their anonymity. What is more, they were informed that there was no non-scientific goal behind the research. All participants were informed that they had the right to leave the interview at any stage without explanation.

\section{Results}

The current study aims to explore the processes underlying the membership in PS in Iran. The emerged themes from the participant observation and interviews are classified into the seven main categories: (1) invitation; (2) systematic promises; (3) working fence; (4) authoritarian psychology of achievement; (5) social construction of superhuman; (6) the fantasy of successful superhuman: a hyper-reality; and (7) double wandering. In the following, we elaborate on each emerged category.

\section{Invitation}

The recruitment process in studied PS is extensively accessible to the extent that this advantage allows such firms to spread fast. Creating an account on the provided website and paying a pre-established minimum amount is all the new members are supposed to do. Inviting relatives and friends is at the top of the recruitment program established by the schemes. Put differently, the priority of invitation is entirely according to the existing intimacy.

Not surprisingly, some discussed that PS function as "moral enterprises" (Schiffauer 2018) that exploit the members' social trust to profit. Conducting business in private settings can result in the misusing of relatively high confidence (Kong 2003; Groß and Vriens 2019). Non-members are usually approached via two main channels: phone and in-person invitations. Contrary to our expectation, the phone invitation is strongly recommended by the PS-since this kind of communication allows members to have strict control over the conversations, cutting it off when necessary. As Mohaddeseh and Shohreh state respectively:

We call on the phone when we want to invite; it is better not to be in person. Personal invitations may cause some excuses or some questions that you cannot answer. When you call someone, you can control the dialogues; you can continue, you can end, or whatever.

We did not let him ask too much. We put off questions to the consultation meeting. We made him curious, and then he came to the next meeting and understood what it was and then asked his real question.

\section{Systematic Promises}

Various tactics are employed by schemes to make their activity attractive to new members. The most frequent one is to focus on what schemes introduce as the "law of opportunities," as Esmaeel elaborate: 
They say that there is a law, 1990 law. I do not know if you heard or not about the law of opportunities. We say that the 1990 law is the law of opportunities that says the first 1 [percent]! It means $1 \%$ of people do something that the other $99 \%$ mock this $1 \%$ !

As demonstrated by Esmaeel's statement, the law of opportunities refers to the idea that members are unique because of their membership in the scheme. Considering superiority for their members, the PS aims to motivate new members while simultaneously construct the identity based on the differentiation assumption (Hall and Du Gay 1996). What is more, the inviters attribute a hyper-realistic characteristic to the current members via exaggerating the benefits attained (Liu 2018); meantime, they refuse to answer any challenging issues questioning the firm. As Koehn (2001) discussed, promises made by the schemes, that is, "get rich quick," play an essential role in the attractiveness of the scheme. What Mehran remembers displays that the schemes were not presented truthfully to the new members: "I just told something attractive to them [new members] to convince them to join."

Superiors, the so-called "upliners," teach members how to persuade people to buy the scheme's product, mainly in a deceptive way. Members are highly recommended to utilize any verbal communication to sell the product, even lying. As Zohreh state in this regard:

[They told us], for example, don't tell them that you used this hair color if you don't really use it or tell them it was good if you're good at lying, but she understands because your hair is not colored! Tell them your sister has used this, and it works well for her. He said to say so if you're good at this.

The abovementioned statement sheds light on how the schemes sell their products-unethically via overestimating the quality of inferior quality products. Moreover, what Mostafa stated demonstrate that such training is issued to members from top to bottom of the scheme in an authoritative way:

As far as I remember, after recruiting three newcomers, we had to learn to tell them about selling [presenting them], after completing the $4^{\text {th }}$, then we'd tell the nine principles ${ }^{1}$ [Motivational book]. This had come from top to bottom. It means that the one on the top had said this, and it had come to the bottom in this way.

The schemes held official celebrations frequently, named "Visiontic" and "Badgentic"," in the private gardens, which members financially cover. These events are organized to promote the attractive aspects of the firm through representing members' realized desires. As Zohreh describes:

Talking of celebrations, we had a Visiontic celebration. For example, we had celebrations for people who had achieved one of their goals after working for a while; or a person who had ticked something off their bucket list. And they had to pay for these celebrations.

\section{Working Fence}

In the beginning, PS put their efforts into recruiting new members and then internalize favorable

\footnotetext{
${ }^{1}$ It refers to nine basic principles of success emphasized by the firm. The principles mainly imply the obedience of the leaders, transfer of experiences, and belief (inspired by popular stories).

${ }^{2}$ During these monthly meetings, the members were supposed to present their goals, which they would strive to attain in the following month. At the end of that month, those who succeeded in achieving the goals, described them and became the socalled "Visiontic."

${ }^{3}$ Refers to those who reach the considerable sales volume and the acceptable team numbers (subordinates). They receive the symbols from the firm and set them on their clothes.
} 
values. Several formal meetings are held weekly to the extent that newcomers feel fully engaged in the schemes. As Shohreh describes: "I would pass from 8 am to 8 pm for training." During meetings, experienced members gradually promote members' communication skills, preparing them to serve the scheme. As Farideh and Ehsan describe respectively:

They taught communicative skills, not to be shy and other things. My senior once said: "I've always been shy, for example, I could not speak, and now I'm here, and I'm talking." Now he holds great seminars and easily stands and speaks for 200 people!

They asked us to talk firmly, heads above, look strong, hold our chest tight, be dandy, and have such and such style.

According to what the participants stated, the organized meetings are posited in the center of the persuasion process. The held meetings or gatherings lead the newcomers to change their behaviors to match the responses of others-recognized as the conformity process (Cialdini and Goldstein 2004). That is why the firms persistently insist on organizing events weekly. The newcomers' information processing is highly adapted according to the majority and minority influence. They are urged to make their judgments in line with the numerical majority to reduce uncertainty (David and Turner 1996). Besides, the newcomers are continually bombarded with the amount of information that is highly simplified; Mansoureh elaborates in this regard:

They kept showing us educational video clips; for example, they introduced different books so that we can give an example while we are teaching others.
The participants also frequently stated that irrelevant information is instructed in the held unceasing meetings to the degree that the interviewees sometimes believe that schemes financially benefit them. The upliners are also invited to the arrangements for giving lectures about their success. Before that, their credentials are ostentatiously shown by the other upline members. What Yousef stated depicts, again, untruthful promises made by the schemes (Groß and Vriens 2019):

Well, when I come, I come with plans. Now we have to see what the aim of a certain arrangement is. It's not for the network; it's for earning money and making a profit. It's for gaining profit. I speak in a way that entices people to order products. I give you inspiration based on whatever you ought to do-so that for a month, you believe that you can be successful.

\section{Authoritarian Psychology of Achievement}

While schemes claim to benefit from selling products, the profitability is mainly based on extensive enrollments. Accordingly, the upliners continually share a set of subtle skills of selling and recruitment, which are immoral. What Mostafa and Mahsa state is noteworthy:

You see this glass that has no value, and its actual price is 1,000 Rials ${ }^{4}$ [less than one cent], but I could sell this to you for 50,000 Rials [around thirty cents]. I mean that I could convince you to buy this for logical reasons; it's so weird! I mean, it really works!

For example, the book Napoleon by Hills, other books such as Grow Rich! With Peace of Mind, The Master-Key to Riches (which is also by Hill), Awaken the Giant With-

$\overline{{ }^{4} \text { Iranian currency. }}$ 
in by Robbins, Prosperity by Randy Gage, The Instant Millionaire: A Tale of Wisdom and Wealth by Fisher, Who Moved My Cheese by Brian Tracy.

What is more, upliners introduce documents, for example, books, clips, and photos that present what they name as "psychology of achievement." Whereas the schemes insist on the advanced scientific base of the psychology of achievement, the training is offered widely through a distorted form accompanied by overstated promises. The primary assumption behind what is publicly known as the psychology of achievement is that the more people think about a goal, the more they are likely to achieve it. Besides, the so-called psychology of achievement recognizes individuals as fully responsible for their fates via trivializing all contextual factors. It is noteworthy that the outlined pedagogy has already been stretched out among non-members. Of the proven potential motivating strength of the pedagogy among society, PS pervasively employ it as a practical toolkit to stimulate and keep the members committed.

\section{Social Construction of Superhuman}

Throughout the held meetings, recruiters mainly focus on their achievements, presenting what they gained recently. To make the audience emotionally excited, the upliners even utilize unconventional language and manners. As Zohreh remembers:

One of these men talked about his success in buying a house in 2 years. He spoke very excitedly, so he suddenly threw a bottle towards people while he was talking to make them clap and shout, and people did so, and it was like, "Now we are excited!" People were excited there, and I wondered what does this mean?! Or someone who was talking normally sud- denly started shouting, "I can do this, you can do this, too, how dare you not!" Suddenly, the tone of his talk changed.

The meetings are mainly organized to evoke new members via accentuating dreams. Newcomers are firstly asked to write all that they dream about and then to imagine they have attained it. Mahsa states while laughing:

They said you are going to achieve your wishes if you write them down. Then put them on the wall and look at them every day. You will reach them if you do this. They said to write down your wishes, and, you know, sometimes it was enjoyable. Write down your wishes with details. For example, if buying a pair of socks is one of your wishes, specify its features and write them down. Write everything in detail. Then, in weekly meetings, they asked members to come forward and tell their wishes and tell what they want to do and what wishes they have for the coming years. ${ }^{5}$

Provoking the motivations, the schemes mostly use the psychology of achievement; that is, all wishes will be accomplished only if people consistently think about them. Therefore, the newcomers come to the idea that their dreams will be realized soon. Otherwise, they must feel guilty because of their faults and shortages. What Tahereh stated demonstrates that what is publicly known as positive psychology is trained by the schemes:

They say, Brian Tracy, in their words, is known to everyone, [even] those who made The Secret movie, ${ }^{6}$ all

\footnotetext{
${ }^{5}$ These meetings were known as "share-vision," in which people tell others about their wishes monthly.

${ }^{6}$ The Secret is a 2006 Australian-American documentary film by Drew Heriot.
} 
say the same thing. They say imagine your dreams, you can't reach them if you don't; you can't reach what you haven't seen.

Over time, new members imagine that they attain their aspirations only through their efforts, assuming that the individuals are competent agents in accomplishing good or evil. Therefore, the upliners also put their efforts into convincing new members that achieving aspirations is to make "vibrations" in the universe. According to the experienced members, vibrations are made mainly via writing up personal ambitions. Besides, they also provoke the new members to think positively, being purely optimistic, and ignoring negative impressions. In this vein, they strictly ask the members not to use negative words. Zohreh describes the situation as follows:

Based on the law of attraction, you should not think negatively; you should not think badly, no negative words, and so on. Instead, think about success to attract it.

\section{The Fantasy of Successful Superhuman:}

\section{A Hyper-Reality}

The atmosphere of PS is optimistic, valuing the positive form of thinking. Consequently, self-confidence among members escalates rapidly. As Yousef remembers, "They raised you to the ceiling [increased your self-confidence], to the extent that if approached people refused to accept the invitation, you couldn't stand it." What Mostafa states shows that the schemes persistently impose specific behavioral patterns on their members: "For example, they [upliners] told us not to do some specific things, do not listen to that kind of music, and so on. Things that were bad for people like us. I mean, you got away [from other people]." The schemes, thereby, encapsulate the members socially and ideologically (Pratt 2000). First, the schemes establish social fences via overloaded work schedules. This keeps the new members away from others. Then, as outlined here, the schemes dictate a kind of lifestyle to the members. The process builds an identity based on inspiring the members that they are different.

The network-based feature of schemes intensifies identity construction by allowing members to introduce themselves as distinguished people. So the members, proud of such differentiation, tend to internalize the scheme values more and more. Accordingly, the members would cultivate a hyper-real imagination about the PS's possibilities and achievements. The dream of becoming rich fast is the primary motivation to immerse in the firms' activities. As Yasamin reflects:

Ms. Niayesh, one of my relatives, used to drive a "Pride" to work, but now she has bought a Bugatti, her income has increased, she has changed her house, and she says all of these are because of the firm. She has even recruited her husband, her husband has left his old job, and now he is working in this firm.

\section{Double Wandering}

Although the organized meetings by the schemes firstly function as "group glue" keeping members together and away from non-members (Pratt 2000), they begin to get boring after a short period, once the recruited members do not experience the positive vibes. As Mahsa elaborates:

\footnotetext{
${ }^{7}$ A type of vehicle in Iran that is generally known as a very cheap and unsafe car.
} 
The first meetings were good, but after a while, everything became boring, everything they said. There was nothing consistent with reality. When I asked them about that, they told me it's the beginning; it won't be like this after you get income. You need more time to fit in.

Trying to invite new members, the inviters face different reactions-some approached people decisively refuse, particularly facing the perseverance of inviters. The inviters, in return, get seriously disturbed when they guess that their friends and acquaintances distrust them. Some approached ones may accept the invitation, joining the scheme primarily due to the inviters' credibility and mutual trust. However, as soon as the newly joined members realize their failure to achieve the firm's promises, they cut off from the inviters. Some also use negative propaganda against inviters, resulting in the elimination of the inviters' credibility. As Esmaeel states: “This work ruins the friendships." Esmaeel also describes the situation as follows:

It would make many people lose their friends. For example, I wanted to bring my close friend to this work, but he didn't come. One leader told me, “Look, go and tell him to come for me, do this, and you will succeed, don't you have trust in me?" Then I told that to my friend, and he said, "No," and our friendship broke down.

Acquaintances and friends leave the inviters gradually and even put an end to their connection with the inviter. Losing their reputation, the inviters also would be rejected by close friends and relatives. As Mahnaz states: “The way others treated us changed, my aunts usually say, 'Here she comes again to deceive us and sell her dodgy products!'” In some cases, families take a defensive stance against the invit- ers, diminishing the inviters' dignity. As Fatemeh describes:

My dad didn't agree with this work at all. So I spoke a lot with him, and I told him that I would prove it. But, now he mocks me and says, "You proved well!"

Over time, challenges and facing the actual world lead members to realize the gap between assumed imaginations and reality. Consequently, members believe that they have dedicated their capital, including time, money, and reputation, to the firms' activities, whereas they have gained nothing in return. As Farzaneh reflects:

You know, it was hard for him to explain to me, as I was his subordinate. He used to tell me his great wishes, and now he works at the railway. The one who used to say my vision is to buy a Kia Optima, ${ }^{8}$ I want to drive my Optima to the hotel where my wedding ceremony is, now he's married, and he is working on the railway, and there is no Kia Optima.

\section{Discussion}

The current study aimed to explore the social process underlying PS embedded in the less addressed social setting, Iran. According to what we explored here, participation in schemes leads to the multistage process of identity construction. Firstly, members are disconnected from non-members via established working fences. This finding is consistent with that of Pratt (2000), who conceptualized it as a social encapsulation process. In Bourdieu's words (1984), the studied schemes internalize their proposed habitus by dominating members' experiences. Introducing their pedagogies as scientif-

\footnotetext{
${ }^{8}$ Referring to an expensive vehicle.
} 
ically supported materials, the upliners put their efforts into internalizing the schemes' favorable values and attitudes. The unattainable promises are massively made to recruit new members and keep them committed to the scheme. Utilizing pedagogies, schemes induce a unique sense to the members-they are fully capable of achieving the promises; otherwise, they are responsible for the failure.

On the one hand, the PS benefit from the pedagogy to build an identity (Kuhn 2006) called superhuman here. The constructed superhumans are supposed to obsessively think positive, considering all aspirations attainable without attention to the real-world restrictions. Boosting members' self-confidence, superhumans recognize themselves as differentiated from non-members, feeling an exaggerated eupho-

\section{References}

Akbarzadeh, Nasrin. 1995. “The Study of the Effect of Iran's Social-Economic Conditions in the 60-70 Decade on the Wishes of Adolescents in Tehran." Journal of Humanities 13(14):29-45.

Albaum, Gerald and Robert A. Peterson. 2011. "Multilevel (Network) Marketing: An Objective View." The Marketing Review 11(4):347-361.

Alvesson, Mats, Karen Lee Ashcraft, and Robyn Thomas. 2008. "Identity Matters: Reflections on the Construction of Identity Scholarship in Organization Studies." Organization 15(1):5-28.

Biebricher, Thomas and Eric Vance Johnson. 2012. “What's Wrong with Neoliberalism?" New Political Science 34(2):202-211.

Bosley, Stacie and Maggie Knorr. 2017. "Pyramids, Ponzi and Fraud Prevention: Lessons from a Case Study." Journal of Financial Crime 25(1):81-94. ria. The constructed superhuman, then, defeats in facing reality and its limitations. Therefore, members experience double wandering-losing their financial resources while being rejected by their friends and relatives.

The findings from this study, in line with the literature (Koehn 2001; Moisander, Groß, and Eräranta 2018; Groß and Vriens 2019), highlight the unethical aspects of MLM, and particularly PS, that are based on misleading information and unfulfilled promises, and exploiting the members' relations. Though we attempted to represent all members of PS in the sample, the analysis was prone to overrepresenting the perspective of young members. Despite efforts to overcome such dilemmas through iterative analysis and an external audit, we acknowledge this limitation.

Bourdieu, Pierre. 1984. Distinction: A Social Critique of the Judgment of Taste. Cambridge: Harvard University Press.

Bourhis, Richard Y. et al. 1997. "Towards an Interactive Acculturation Model: A Social Psychological Approach." International Journal of Psychology 32(6):369-386.

Brewer, Marilynn B. and Wendi Gardner. 1996. "Who Is This 'We?' Levels of Collective Identity and Self Representations." Journal of Personality and Social Psychology 71(1):83-93.

Cahill, Damien. 2011. "Beyond Neoliberalism? Crisis and the Prospects for Progressive Alternatives." New Political Science 33(4):479-492.

Carspecken, Francis Phil. 1996. Critical Ethnography in Educational Research: A Theoretical and Practical Guide. New York: Routledge. 
Charmaz, Kathy. 2006. Constructing Grounded Theory: A Practical Guide through Qualitative Analysis. London, Thousand Oaks, New Delhi: Sage.

Cialdini, Robert B. and Noah J. Goldstein. 2004. "Social Influence: Compliance and Conformity." Annual Review of Psychology 55:591-621. doi: 10.1146/annurev.psych.55.090902.142015.

Comaroff, Jean and John L. Comaroff. 2000. "Millennial Capitalism: First Thoughts on a Second Coming." Public Culture 12(2):291-343.

Creswell, John W. and Dana L. Miller. 2000. “Determining Validity in Qualitative Inquiry." Theory Into Practice 39(3):124-130.

David, Barbara and John C. Turner. 1996. "Studies in Self-Categorization and Minority Conversion: Is Being a Member of the Out-Group an Advantage?" British Journal of Social Psychology 35(1):179-199. doi: 10.1111/j.2044-8309.1996.tb01091.x.

Deliema, Marguerite et al. 2018. "AARP Study of Multilevel Marketing: Profiling Participants and Their Experiences in Direct Sales 2018." Retrieved July 26, 2021 (https://www.aarp. org/content/dam/aarp/aarp_foundation/2018/pdf/AARP\%20 Foundation\%20MLM\%20Research\%20Study\%20Report\%20 10.8.18.pdf).

DeRue, D. Scott and Susan J. Ashford. 2010. “Who Will Lead and Who Will Follow? A Social Process of Leadership Identity Construction in Organizations." Academy of Management Review 35(4):627-647.

DeRue, D. Scott, Susan J. Ashford, and Natalie C. Cotton. 2009. "Assuming the Mantle: Unpacking the Process by which Individuals Internalize a Leader Identity." Pp. 213-232 in Exploring Positive Identities and Organizations: Building a Theoretical and Research Foundation, edited by L. M. Roberts and J. E. Dutton. New York: Taylor \& Francis.

Dyer-Witheford, Nick. 1999. Cyber-Marx: Cycles and Circuits of Struggle in High-Technology Capitalism. Urbana, IL: University of Illinois Press.

Eckhardt, Giana M., Nikhilesh Dholakia, and Rohit Varman. 2013. "Ideology for the 10 Billion: Introduction to Globalization of Marketing Ideology." Journal of Macromarketing 33(1):7-12.

Effiom, Lionel and Francis Archibong Effiong. 2015. “The Role of Multilevel Marketing (MLM) in Poverty Alleviation in Calabar Cross River State, Nigeria: A Case Study of Forever Living Product (Nig.)." Social Sciences Research Journal 2(2):150-163.
Franco, William and Maria A. Gonzalez-Perez. 2016. "International Expansion Ppportunities for Multilevel Marketing via Personal Networks: An Ethnographic Study from Colombia." International Journal of Business and Society 17(1):28-46.

Gioia, Dennis A. et al. 2013. “Organizational Identity Formation and Change." Academy of Management Annals 7(1):123-193.

Grayson, Kent. 2007. "Friendship versus Business in Marketing Relationships." Journal of Marketing 71(4):121-139.

Greenwald, Rachel. 2010. Have Him at Hello: Confessions from 1,000 Guys about What Makes Them Fall in Love... Or Never Call Back. New York: Three Rivers Press.

Gregor, Bogdan and Aron-Axel Wadlewski. 2013. Multilevel Marketing as a Business Model. Warsaw: Institute of Aviation Scientific Publishers.

Groß, Claudia and Dirk Vriens. 2019. “The Role of the Distributor Network in the Persistence of Legal and Ethical Problems of Multi-Level Marketing Companies." Journal of Business Ethics 156(2):333-355. doi: 10.1007/s10551-017-3556-9.

Hall, Stuart and Paul Du Gay, eds. 1996. Questions of Cultural Identity: SAGE Publications. London, Thousand Oaks, New Delhi: Sage.

Harvey, David. 2007a. "Neoliberalism as Creative Destruction." Annals of the American Academy of Political and Social Science 610(1):22-44.

Harvey, David. 2007b. A Brief History of Neoliberalism. Oxford: Oxford University Press.

Hyman, Michael R. 2007. "Multilevel Marketing: A Pyramid Scheme by Design." New Mexico State University Business Outlook 1-5. Retrieved July 26, 2021 (https://www.researchgate. net/publication/270902987_Multi-level_marketing_A_pyramid_scheme_by_design).

Koehn, Daryl. 2001. “Ethical Issues Connected with Multi-Level Marketing Schemes." Journal of Business Ethics 29(1):153-160. doi: 10.1023/A:1006463430130.

Kong, Kenneth C. C. 2003. "'Are You My Friend?': Negotiating Friendship in Conversations between Network Marketers and Their Prospects." Language in Society 32(4):487-522. doi: 10.1017/S0047404503324029. 
Krige, Detlev. 2012. "Fields of Dreams, Fields of Schemes: Ponzi Finance and Multilevel Marketing in South Africa." Africa 82(1):69-92.

Kuhn, Timothy. 2006. “A ‘Demented Work Ethic' and a 'Lifestyle Firm': Discourse, Identity, and Workplace Time Commitments." Organization Studies 27(9):1339-1358.

Liu, Heidi. 2018. "The Behavioral Economics of Multilevel Marketing." Hastings Business Law Journal 14(1):109-138.

Makni, Valentina. 2015. "Public Perceptions towards Network Marketing in Bulgaria." Paper presented at the Conference Economy and Politics in the Post-Crisis World, Varna, Bulgaria.

Mauthner, Natasha S. and Andrea Doucet. 2003. "Reflexive Accounts and Accounts of Reflexivity in Qualitative Data Analysis." Sociology 37(3):413-431.

Merton, Robert K. 1938. "Social Structure and Anomie." American Sociological Review 3(5):672-682.

Moisander, Johanna, Claudia Groß, and Kirsi Eräranta. 2018. "Mechanisms of Biopower and Neoliberal Governmentality in Precarious Work: Mobilizing the Dependent Self-Employed as Independent Business Owners." Human Relations 71(3):375-398. doi: 10.1177/0018726717718918.

Muncy, James A. 2004. “Ethical Issues in Multilevel Marketing: Is It a Legitimate Business or Just Another Pyramid Scheme?" Marketing Education Review 14(3):47-53.

Musaraj, Smoki. 2019. “The Magic of Pyramid Firms: Cosmologies of Speculation, Repertoires of Credit and Collapsed Finance." Ethnos 84(2):179-200.

Nat, Peter J. Vander and William W. Keep. 2002. “Marketing Fraud: An Approach for Differentiating Multilevel Marketing from Pyramid Schemes." Journal of Public Policy \& Marketing 21(1):139-151.

Nobre, Helena and Daniela Silva. 2014. "Social Network Marketing Strategy and SME Strategy Benefits." Journal of Transnational Management 19(2):138-151.
Overbeek, Henk and Bastiaan Van Apeldoorn, eds. 2012. Neoliberalism in Crisis. London: Palgrave Macmillan.

Payne, Keith. 2017. The Broken Ladder: How Inequality Affects the Way We Think, Live, and Die. New York: Penguin.

Polanyi, Karl. 1994. The Great Transformation: The Political and Economic Origins of Our Time. New York: Rinehart.

Pratt, Michael G. 2000. "The Good, the Bad, and the Ambivalent: Managing Identification among Amway Distributors." Administrative Science Quarterly 45(3):456-493. doi: 10.2307/2667106.

Pratt, Michael G. and José Antonio Rosa. 2003. “Transforming Work-Family Conflict into Commitment in Network Marketing Organizations." The Academy of Management Journal 46(4):395-418.

Robins, Kevin and Frank Webster. 1999. Times of Technoculture: Information, Communication, and the Technological Order. London: Routledge.

Schiffauer, Leonie. 2018. “Let's Get Rich: Multilevel Marketing and the Moral Economy in Siberia." Critique of Anthropology 38(3):285-302.

Schiffauer, Leonie. 2019. Marketing Hope: Get-Rich-Quick Schemes in Siberia. New York, Oxford: Berghahn Books.

Simon, Roger I. and Donald Dippo. 1986. “On Critical Ethnographic Work." Anthropology and Education Quarterly 17(4):195202.

Stewart, Lee and Kim Usher. 2007. "Carspeckens Critical Approach as a Way to Explore Nursing Leadership Issues." Qualitative Health Research 17(7):994-999.

Tyre, Troy A. 2016. “Network Marketing Essence of Success: An Interpretative Phenomenological Analysis." Business and Management Research Journal 6(4):46-73.

Van Oort, Madison. 2015. "Making the Neoliberal Precariat: Two Faces of Job Searching in Minneapolis." Ethnography 16(1):74-94.

\section{Citation}

Keshavarzi, Saeed, Ali Ruhani, and Soheyla Hajiheidari. 2021. "Mechanisms of Identity Construction among Members of Pyramid Schemes in Iran: A Critical Ethnography." Qualitative Sociology Review 17(4):104-117. Retrieved Month, Year (http://www. qualitativesociologyreview.org/ENG/archive_eng.php). DOI: https://doi.org/10.18778/1733-8077.17.4.06 